\title{
Marginal Abatement Cost Curves for Water Scarcity Mitigation under Uncertainty
}

\section{Karin Sjöstrand, et al. [full author details at the end of the article]}

Received: 28 March 2019 / Accepted: 2 October 2019 /

Published online: 31 October 2019

(C) The Author(s) 2019

\begin{abstract}
As water scarcity and drought become more common, planning to avoid their consequences becomes crucial. Measures to prevent the impact of new climate conditions are expected to be extensive, costly and associated with major uncertainties. It is therefore necessary that policymakers and practitioners in both the public and private sector can compare possible mitigation measures in order to make economically rational investment decisions. For this to be successful, decision-makers need relevant decision support. This paper presents a novel approach of constructing marginal abatement cost curves for comparing water scarcity mitigation measures while taking the underlying uncertainties into account. Uncertainties in input variables are represented by probability distributions and calculations are performed using Monte Carlo simulations. This approach is applied on the island of Gotland, one of the most water-stressed parts of Sweden, to provide the first marginal abatement cost curve in Europe for water scarcity mitigation in which municipal, agricultural, industrial and household measures are compared. The results show that the agricultural measure of on-farm storage has the greatest potential to increase water availability on the island. Among municipal measures, increased groundwater extraction and desalination offer the greatest potential, although desalination is almost 25 times more costly per cubic meter. The most cost-effective measure is linked to hot water savings in the hotel industry. The approach presented provides a quantitative visualization of the financial trade-offs and uncertainties implied by different mitigation measures. It provides critical economic insights for all parties concerned and is thus an important basis for decision-making.
\end{abstract}

Keywords Water scarcity · Drought · Demand and supply management · Water availability · Marginal abatement cost curve · Uncertainty

\footnotetext{
Highlights

- A marginal abatement cost curve approach for well-informed water scarcity mitigation is presented.

- Monte Carlo simulations are used to enable structured uncertainty and sensitivity analyses.

- Agricultural, municipal, industrial and household measures are compared in a systematic and transparent way.

- For the island of Gotland, new irrigation dams have the largest potential to increase water availability.
}

Electronic supplementary material The online version of this article (https://doi.org/10.1007/s11269-01902376-8) contains supplementary material, which is available to authorized users. 


\section{Introduction}

Water scarcity and drought are considered to be among the most critical global risks to society (WEF 2019) with short and long-term effects on citizens, ecosystem services, biodiversity and the economic sectors that depend on a reliable water availability. In Sweden, which is considered to have good access to natural water resources, only $1 \%$ of the renewable water is extracted for use in households, agriculture and industry (Eurostat 2017). The industry is the main water user in Sweden, accounting for about $61 \%$ of water use. Around $23 \%$ of the water is used by households and $3 \%$ by the agricultural sector. The remaining $13 \%$ is used within other user categories, such as construction, retailing, hotel and restaurant, transport, and public administration. Thirty-five percent of total water, and $88 \%$ of household water, is provided via the public water supply system for which the municipalities are responsible (Statistics Sweden 2017). However, both water usage and water availability vary largely across the country and do not always overlap geographically. Hence, local water imbalances are not uncommon, and the southern, central and coastal areas along the Baltic Sea in particular may experience water shortages during the summer (Statistics Sweden 2017). Nevertheless, the low precipitation and high summer temperatures that hit Sweden for the third consecutive year in 2018 acted as a wake-up call. The vastly reduced access to water had major consequences for the Swedish society, with failing crop yields and comprehensive emergency measures to maintain the water supply to households, industry, and critical societal functions. In the summer of 2018, around $30 \%$ of the municipalities prohibited urban irrigation and called for careful use of drinking water. Farmers experienced their worst harvest since the 1950s, and the lack of grazing and feed led to emergency slaughter of livestock and six-month queues to the slaughterhouses (Sjökvist et al. 2019).

Planning to avoid and manage water scarcity is an expanding area within integrated water resource management (IWRM), see e.g. Dukhovny et al. (2013). In 2007, the European Commission presented an initial proposal on how to address and mitigate the challenges posed by water scarcity and drought within the European Union (EC 2007). In line with the IWRM literature, the ensuing European Commission reports emphasized that the most appropriate way to address water scarcity and drought is to use an integrated approach based on a combination of demand and supply measures. However, additional water supply infrastructures, such as water transfer and desalination plants, are to be carried out only after all demandside measures have been considered. Demand and supply management measures can be broadly categorized as: 1) measures that increase the water supply by converting natural resources into available and reliable water; 2) measures that reduce demand by encouraging efficient and controlled water use; and 3) measures that increase productivity, e.g. via improved practices and water reuse (Addams et al. 2009; Pinto and Marques 2017). Measures to prevent the water-related impacts of climate change are expected to be extensive and costly (Westling et al. 2019). Furthermore, the quality of data relating to such measures can be highly variable and uncertain (Addams et al. 2009). Hence, it is necessary that policymakers and practitioners are provided with relevant decision support that would allow them to compare the range of possible mitigation measures and make economically rational investment decisions.

In climate policy-making, marginal abatement cost curves (MACC) are frequently used to provide guidance on greenhouse gas (GHG) mitigation measures. MACCs have gained in popularity since they succeed in illustrating and comparing a range of complex measures from various sectors in an easily understandable format. The curves specify the marginal cost of abatement for each analyzed measure while enabling assessments to be 
made of the total abatement costs through the integral of the curve (Kesicki 2012). MACCs have been used for GHG assessments in a variety of sectors, e.g. the cement industry (Worrell et al. 2000), the transport sector (Peng et al. 2018), and forestry and agriculture (Eory et al. 2018a; Moran et al. 2009). MACCs have also been used in other policy areas but only a few studies have applied them to water challenges (Addams et al. 2009; Chukalla et al. 2017). Most MACC studies do not take the influence of uncertainty into account, but often highlight the difficulty of including uncertainties in the cost curve format (Kesicki 2012). The limited representation of uncertainty has led to concerns that the cost curves give an impression of robustness without showing the underlying uncertainties (Eory et al. 2018a). By ignoring the influence of uncertainties, the usefulness of the MACCs is reduced. The MACC studies that have quantified uncertainties have most often been limited to analyzing one or two specific parameters, such as the discount rate, through scenario or sensitivity analysis (Peng et al. 2018). Recently, Peng et al. (2018) and Eory et al. (2018b) presented statistical uncertainty analyses based on Monte Carlo simulation for MACCs in the transport and agricultural sectors. However, there is no commonly accepted state-of-the-art approach to performing uncertainty analysis of water scarcity mitigation measures in a MACC context. Addams et al. (2009) acknowledged this and welcomed contributions that could improve their MACC framework by addressing uncertainties associated with water challenges. This paper attempts to meet that need.

The primary aims of this paper are therefore to: 1) provide systematic handling of uncertainties in MACCs of water scarcity mitigation efforts; and 2) exemplify the MACC approach by evaluating and comparing municipal, industrial, agricultural and household mitigation efforts on the island of Gotland, one of the most water-stressed parts of Sweden. The MACC is based on financial analysis that demonstrates the financial trade-offs implied by different mitigation measures, thus providing critical economic insights for all parties concerned and an important basis for reaching decisions. Making this approach available in the literature is a valuable contribution to the economics of water scarcity mitigation through which the uncertainties behind narrowing the water deficit become apparent.

\section{The Island of Gotland}

Gotland is Sweden's largest island, located in the Baltic Sea about $100 \mathrm{~km}$ from the mainland. The annual precipitation on the island is approximately $550 \mathrm{~mm}$. However, thin soil layers, extensive drainage, and a lack of coherent reservoirs in the sedimentary limestone bedrock lead to high precipitation run-off. The number of people who live on Gotland all year round is about 58,000, just a fraction of the vast number of visitors. In 2016 over 2 million people traveled to Gotland, and the number of guest nights at hotels and other commercial accommodation facilities exceeded 1 million (Region Gotland 2017). The peak season for tourism is during the summer, resulting in a large seasonal variation in water demand and with the highest demand occurring when water supplies are at their lowest. Compared to other parts of Sweden, the water supply system of Gotland is built on a large proportion of private solutions, with only $67 \%$ of the households connected to the public water supply system. Around $65 \%$ of the public water supply system relies on groundwater. The remaining $35 \%$ of the water comes from lakes and one desalination plant (a further desalination plant is currently under construction). 
Gotland is a single municipality and due to its geographical location, there is no possibility of augmenting the water supply from neighboring municipalities. For short-term water supply disruptions, an emergency plan will assure water distribution to supply important societal activities. For longer disruptions however, e.g. in connection with extended periods of low water availability, there is no plan for how to continue to provide water to the community. In addition to an already constrained water supply situation, it is estimated that the total water demand on the island will increase by more than $40 \%$ through to 2045 (Table 1). This will require water that is currently not available on the island (County Administrative Board of Gotland 2018).

\section{Methodology}

\subsection{Marginal Abatement Cost Curves}

There are two different method approaches that can be employed to construct MACCs: an expert-based approach and a model-based approach (Chukalla et al. 2017). An expert-based approach focuses on assessing the cost-effectiveness of individual measures based on expert input, enabling the inclusion of high technological detail in the assessments. A model-based approach derives the costs and potentials from different model runs. The strengths and weaknesses of the two approaches are discussed in Kesicki (2010) and Kesicki (2012). This paper applies the expert-based approach.

The MACC developed for this paper shows the cost of adding or conserving water, i.e. increasing water availability by one unit compared to a reference scenario. The measures are ranked and displayed as bars on the curve in order of cost to increase water availability, from the cheapest to the most expensive, see schematic description in Online Resource 1. The height of each bar represents the cost per unit of water added or conserved by the measure in SEK per cubic meter (100 SEK $\approx 11$ USD - March 2019),

Table 1 Recent and forecast water demand on the island of Gotland (County Administrative Board of Gotland 2018)

\begin{tabular}{llll}
\hline Sector & $\begin{array}{l}\text { Water use in } \\
2015\left(\mathrm{Mm}^{3} / \text { year }\right)\end{array}$ & $\begin{array}{l}\text { Forecast change } \\
\text { to } 2045\end{array}$ & $\begin{array}{l}\text { Forecast demand } \\
2045\left(\mathrm{Mm}^{3} / \text { year }\right)\end{array}$ \\
\hline $\begin{array}{l}\text { Households } \\
\text { - Municipal water }\end{array}$ & 2.5 & & \\
$\begin{array}{l}\text { - Private water } \\
\text { Animal keeping }\end{array}$ & 1.2 & $+20 \%$ & 3 \\
$\begin{array}{l}\text { - Municipal water } \\
\text { - Private water }\end{array}$ & 0.2 & $+20 \%$ & 1.4 \\
$\begin{array}{l}\text { Tourism etc. } \\
\text { - Municipal water }\end{array}$ & 1.3 & $+100 \%$ & 0.4 \\
$\begin{array}{l}\text { - Private water } \\
\text { Industry }\end{array}$ & 1.3 & $+5 \%$ & 1.4 \\
- Municipal water & $\mathrm{NA}$ & & \\
- Private water & 0.3 & $+30 \%$ & 1.7 \\
$\begin{array}{l}\text { Irrigation } \\
\text { Total }\end{array}$ & 5.8 & $\mathrm{NA}$ & $\mathrm{NA}$ \\
\hline
\end{tabular}


and the width of each bar represents the annual amount of water made available by each measure in cubic meters.

\subsection{Selection of Mitigation Measures}

There are many potential ways of increasing water availability. One initial task in this study was therefore to find a relevant subset of measures to be analyzed and compared for the island of Gotland. A multidisciplinary expert workshop held on Gotland in April 2018 was used as a platform to identify this subset of measures. The workshop brought together 49 participants representing the following stakeholder categories: mining industry, water utilities, politicians, tourism, agriculture, scientific community, food industry, housing, community planning, and environmental professionals.

The workshop participants were divided into eight groups with as large representation from each stakeholder category as possible in each group. The participants were asked to collectively identify, discuss and reach a consensus on which measures within the tourism, mining, food, agriculture and municipal sectors were the most promising means available to improve water availability on the island. The measures could be general and could potentially be performed by many or all practitioners in the sector, or they could be specific to an individual practitioner. The workshop participants were also asked to discuss the practical feasibility of the measures and to list drivers and barriers for implementation.

As a result of the workshop, a list of measures was identified. This list was further modified during discussions with expert groups from the different sectors, taking into account the practical feasibility of the measures and their applicability to the conditions prevailing on Gotland; the availability of data to make proper cost and water availability estimations; the risk of negative co-effects; and the extent to which the measures would increase water availability. The final list of measures included in this study is presented in Table 2. All selected measures can be realized individually, and they are therefore not dependent on each other for their implementation. However, it is important to note that the measures are not exclusive; improved water availability can also be achieved by other measures.

\subsection{Calculation of Water Availability Potential}

The potentials of selected measures were estimated in relation to a reference scenario. The reference scenario was based on current water usage and on forecast demand over the time horizon 2019-2045, as shown in Table 1. The reference scenario did not consider any other changes in demand and supply, e.g. due to assumed political or corporate decisions regarding mitigation measures.

The potential water quantity added or conserved by each measure is a function of the technical potential of the measure, its applicability in the specific region, and on the level of adoption. A combination of national and local literature data and expert opinions was used to identify and estimate the parameters needed to calculate the technical potential and applicability of the measures on Gotland. The municipal, agricultural and industry experts were local practitioners with experience from implementing measures similar to those analyzed here. The household sector was represented by consultants and technology providers. The technical potential was estimated on an annual unitary basis, e.g. water saving per household or water added per hectare of agricultural land. This was then multiplied by an applicability metric to calculate the annual water availability potential for Gotland. The applicability metric captures 
Table 2 Final list of measures aimed at increasing supply (S) and decreasing demand (D) for inclusion in the MACC

\begin{tabular}{|c|c|c|}
\hline Sector & Mitigation measure & Short description \\
\hline Municipality & Leakage detection (S) & $\begin{array}{l}\text { Extended active leak detection, using district-metered areas in } \\
\text { which the flow is univocally measured. }\end{array}$ \\
\hline Municipality & Desalination (S) & $\begin{array}{l}\text { Reverse osmosis desalination and transport of treated water to } \\
\text { demand centers. }\end{array}$ \\
\hline Municipality & Surface water extraction (S) & Increased surface water extraction. \\
\hline Municipality & Groundwater extraction (S) & Increased groundwater extraction. \\
\hline Municipality & Artificial recharge $(\mathrm{S})$ & Artificial groundwater recharge in existing water supplies. \\
\hline Municipality & Wastewater for irrigation (S) & Improved wastewater treatment with UV for irrigation. \\
\hline Household & Rainwater harvesting $(\mathrm{S})$ & $\begin{array}{l}\text { Collection and treatment of rainwater to drinking water quality at } \\
\text { single-household units. }\end{array}$ \\
\hline Household & Small-scale desalination (S) & $\begin{array}{l}\text { Collection and treatment of seawater to drinking water quality at } \\
\text { single-household units. }\end{array}$ \\
\hline Household & Vacuum toilets (D) & Installation of vacuum toilets in single-household units. \\
\hline Household & Graywater reuse (D) & $\begin{array}{l}\text { Installation of graywater treatment techniques for non-potable reuse } \\
\text { in single-household units. }\end{array}$ \\
\hline Agriculture & $\begin{array}{l}\text { Sub-irrigation (large-scale) } \\
\text { (S) }\end{array}$ & $\begin{array}{l}\text { Implementation of controlled drainage and sub-irrigation by regu- } \\
\text { lating the riser in the drain outlet. Permit required. }\end{array}$ \\
\hline Agriculture & $\begin{array}{l}\text { Sub-irrigation (small-scale) } \\
\text { (S) }\end{array}$ & The same measure as above but with no permit required. \\
\hline Agriculture & Irrigation dams $(\mathrm{S})$ & Collection of precipitated water in \\
\hline Agriculture & Ramp irrigation (D) & $\begin{array}{l}\text { Conversion from traditional irrigation methods to water-saving } \\
\text { irrigation techniques. }\end{array}$ \\
\hline Industry & $\begin{array}{l}\text { Reuse of mining drainage } \\
\text { water }(\mathrm{S})\end{array}$ & $\begin{array}{l}\text { Treatment of mining drainage water to drinking water quality and } \\
\text { use within the municipal water supply system. }\end{array}$ \\
\hline Industry & $\begin{array}{l}\text { Saltwater pools and toilets } \\
\text { at campsites (D) }\end{array}$ & $\begin{array}{l}\text { Conversion from freshwater to seawater in campsite pools and } \\
\text { toilets. }\end{array}$ \\
\hline Industry & $\begin{array}{l}\text { Retrofit showerheads and } \\
\text { faucets at hotels (D) }\end{array}$ & $\begin{array}{l}\text { Retrofitting showerheads and bathroom faucets with water-saving } \\
\text { devices. }\end{array}$ \\
\hline
\end{tabular}

the feasibility of the measures on Gotland, e.g. only households on the west coast of Gotland that are located within $300 \mathrm{~m}$ of the sea were considered to be feasible for small-scale desalination. This determined the theoretical upper limit of the measures in cubic meters per year by assuming the highest feasible level of adoption.

\subsection{Calculation of Costs and Cost-Effectiveness}

The measure costs included investment costs, operating costs and possible cost savings generated by the measure. The same local expertise as described above was used to identify and estimate costs and cost savings, again in combination with literature data. The cost estimates made by the experts were based on experience from similar completed projects. The costs associated with the measures were presented in the form of present values $(P V \mathrm{~s})$ (Hastings 2015), analyzed over the 27-year time horizon from 2019 to 2045 and based on 2018 prices. The time horizon chosen corresponds to the current water supply plan for Gotland (County Administrative Board of Gotland 2018). The $P V$ for measure $i$ was calculated as:

$$
P V_{i}=\sum_{t=0}^{T} \frac{C_{i, t}}{(1+r)^{t}}
$$


where $C$ is cost, $t$ is the time when the cost occurs, $T$ is the time horizon, and $r$ is the discount rate. The individual costs were attributed as far as possible to the annual time periods in which they were assumed to occur. The technical lifetime for each measure was assumed to be equal to its economic lifetime. If the lifetime of a measure was shorter than the time horizon, reinvestment was assumed. The reinvestment costs were assumed to be equal to the initial investment. Similarly, if the lifetime of a measure was longer than the time horizon, its residual value was calculated using the straight-line depreciation method (Black et al. 2017). The PVs were then expressed as annuities distributed evenly over the time horizon $T$, i.e. as equivalent annual costs (EACs) in SEK per year (Brealey et al. 2010):

$$
E A C_{i}=\frac{r\left(P V_{i}\right)}{1-\frac{1}{(1+r)^{T}}}
$$

Three discount rates were used $(1.4 \%, 3.5 \%$ and $5 \%)$, reflecting the average discount rate used in the Stern Review on Climate Change (Stern 2006) and the suggested social and private rates in the Swedish Transport Administration (2018) guidelines for cost-benefit analysis. The effectiveness of the measures in increasing water availability was calculated as the ratio of the $E A C$ and the annual water availability potential of each measure in SEK per cubic meter. Details of the calculations are provided in Online Resource 2.

\subsection{Uncertainty and Sensitivity Analyses}

Long time horizons imply substantial uncertainties due to lack of available data or knowledge, bias and subjectivity of experts and stakeholders, and natural random variability. Uncertainties in predictions of, e.g. future climate development, may result in uncertainties in the applicability metrics, i.e. to what extent measures can be implemented. There are also uncertainties regarding the magnitude of the technical potential of the measures, as well as investment and operating costs and cost savings and their spatial and temporal variations. To account for uncertainties in data and expert judgements, model variables were defined using probability distributions. Probability distributions could ideally be determined by fitting a density curve to a histogram of the variables' dataset, given the dataset is sufficiently large. For variables where no such dataset is available, the choice of probability distribution can be based on literature information, and the statistical parameters, such as mean value and standard deviation, could be based on a combination of literature data and expert judgements. This paper used the latter version as most variable estimates were based on local, site-specific conditions and consequently no large datasets were available. Experts within each measure category were therefore involved in estimating how the input variables can vary, based on literature data and experience from previous projects.

The lognormal probability distribution was assigned for costs and cost savings, as is common in economics and cost analysis (Garvey et al. 2016). The lognormal distribution can arise from a multiplicative combination of many random variables, and as such it has been found to also fit water availability potential of water conservation measures (Rosenberg 2007). Hence, the lognormal distribution was also assigned to water availability potential. The normal distribution was assigned to applicability metrics, e.g. to the number of houses implementing small-scale desalination. The parameters used to define the normal and lognormal distributions were the mean value and standard deviation of the specific item. 
The calculations of the unit costs were performed using Monte Carlo simulations, i.e. repeated random sampling (here 10,000 iterations) from the input distributions in order to generate probability distributions of the output variables. The Monte Carlo simulations provide information regarding the relative variation in the marginal costs of the measures. The coefficient of variation $(\mathrm{CV})$, i.e. the ratio of the standard deviation to the mean, was used to compare the uncertainties associated with each measure, independent of their cost per cubic meter. Furthermore, the correlation coefficients of the measures were used to assess which input variables had the greatest effect on the outcome uncertainty. The impact of the three discount rates was modelled as three scenarios to determine its effect on the final results.

\section{Results}

Figure 1 demonstrates the MACC for the analyzed agricultural, household, industrial and municipal measures. The MACC is based on the mean values of cost per cubic meter and water availability for each measure. The results presented in Fig. 1 demonstrate that on Gotland, the household measures are the least cost-effective when it comes to providing additional water availability. Agricultural measures, such as increased sub-irrigation and irrigation dams, together with traditional municipal measures, such as increased groundwater extraction, are among the most cost-effective. One measure, i.e. retrofitting showerheads and faucets at hotels, is financially beneficial due to the hot water savings, and subsequent energy savings, that ensue from this measure (Fig. 2).

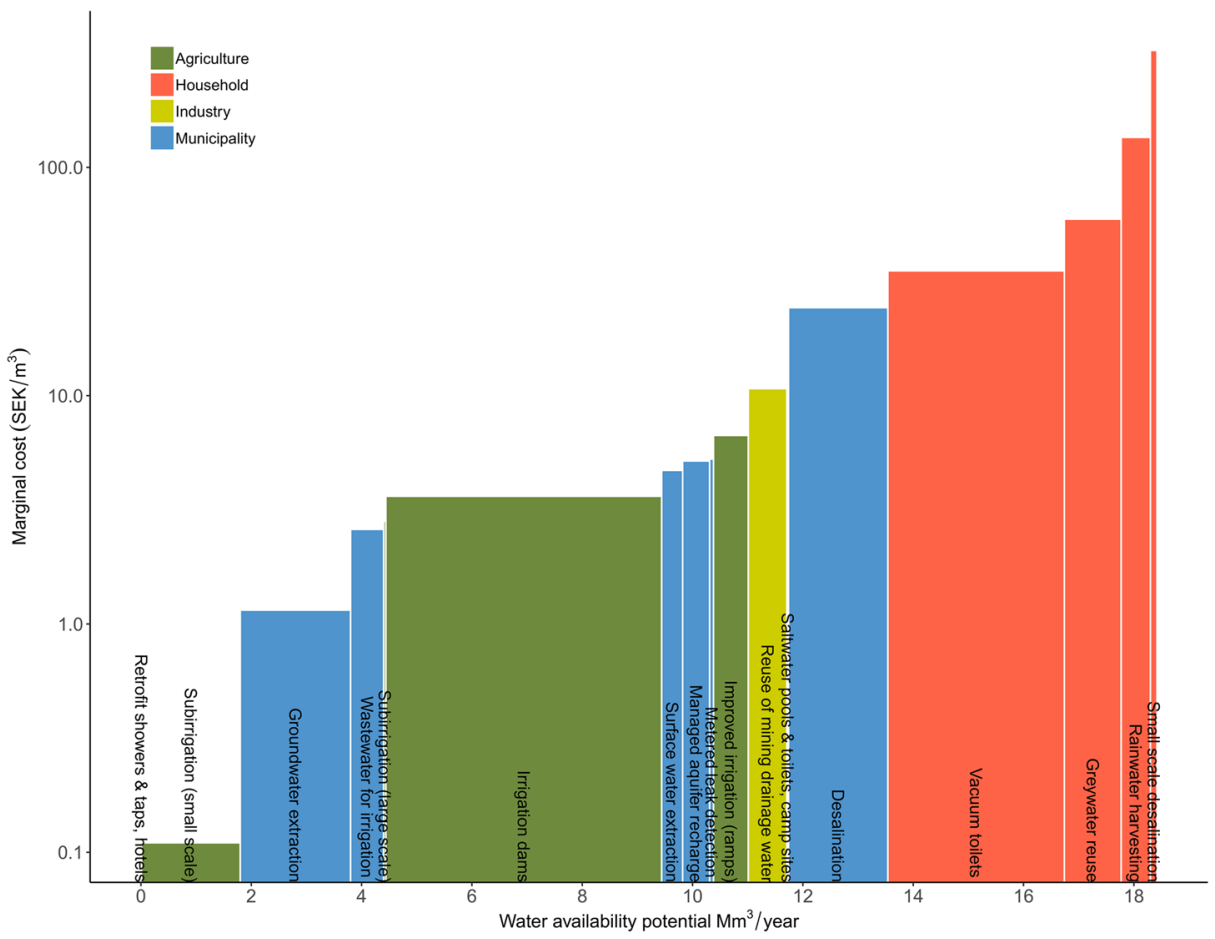

Fig. 1 Marginal abatement cost curve for agricultural, household, industrial and municipal measures based on mean values at a $3.5 \%$ discount rate (note the logarithmic scale on the y-axis) 

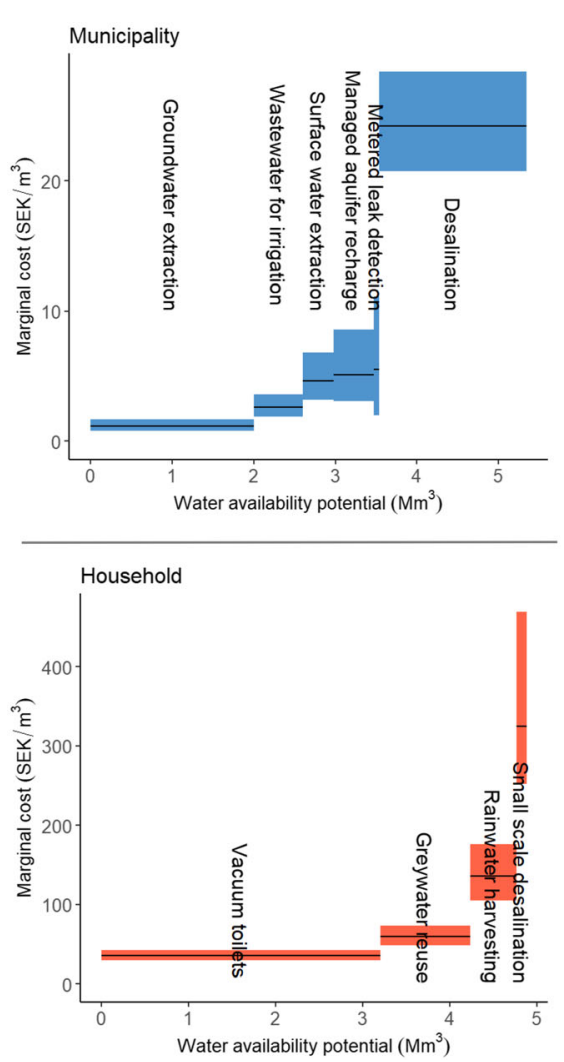
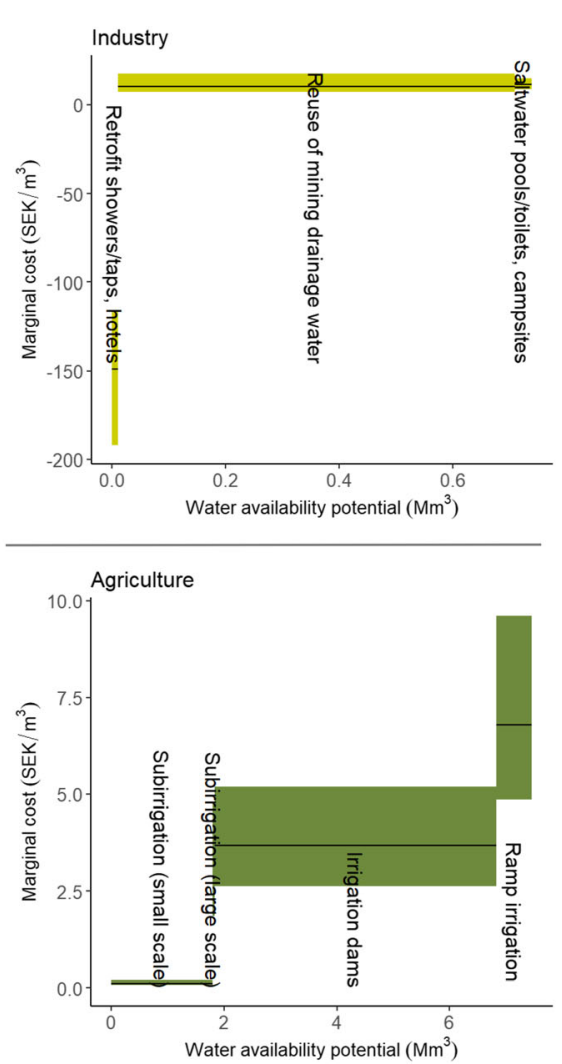

Fig. 2 Municipal, agricultural, household and industrial measures, percentiles P05, P50 and P95 with a 3.5\% discount rate

The largest contributor to water availability potential is the irrigation dams measure, which has the potential to meet the entire forecast irrigation requirements. Of the municipal measures, increased groundwater extraction and desalination offer the greatest water availability potential. However, on Gotland desalination is almost 25 times more costly than increased groundwater extraction, due in part to the long pipelines needed to reach demand centers.

Figure 2 shows the range of uncertainties associated with the cost per unit calculation of each measure. This is illustrated by means of error bars based on the 5th, 50th and 95th percentiles. The water availability uncertainties are included in the cost per unit calculations shown on the $y$-axis, whereas the $\mathrm{x}$-axis is limited to showing the annual mean value only. See Online Resource 3 for water availability uncertainties.

The CVs for the analyzed measures are between 0.10 and 0.74 (Online Resource 4). Of the municipal measures, metered leak detection with a $\mathrm{CV}$ of 0.49 was associated with the largest uncertainties. In the household, industry and agriculture sectors, small-scale desalination $(0.74)$, reuse of mining drainage water $(0.32)$, and small-scale sub-irrigation $(0.34)$ respectively were the measures associated with the greatest uncertainties.

Figure 3 shows the degree to which the input variables of small-scale sub-irrigation co-vary with the marginal cost, expressed using Spearman rank correlation coefficients between -1 and 1. Input variables related to estimates of the sub-irrigated area contributed most to the outcome uncertainty. Correlation coefficients for all measures are provided in Online Resource 5. 


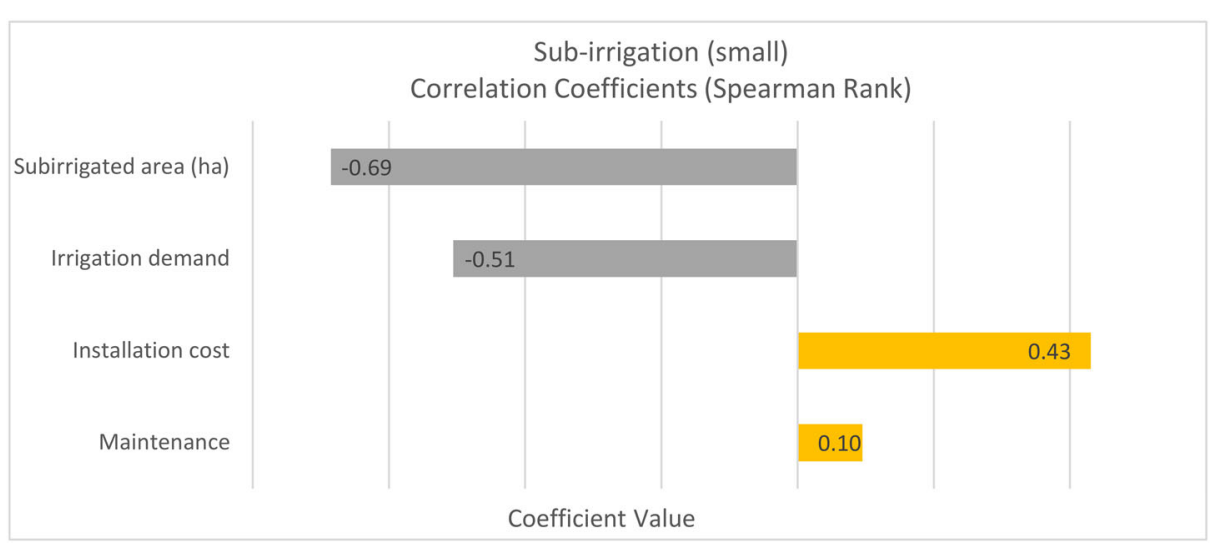

Fig. 3 Correlation coefficients (Spearman rank) of input variables and the cost per unit outcome for subirrigation at a $3.5 \%$ discount rate

The impact of discount rates was modelled using scenario analysis. Based on mean values, the ranking order does not change substantially between the three analyzed discount rates, and not at all for the six highest-ranked measures, indicating a robust cost curve order (Online Resource 6).

\section{Discussion}

A MACC is unique to every region or country for which it is performed. Both the prioritized set of measures and the final ranking order depend on site-specific conditions. This paper has established a projected MACC of water scarcity mitigation measures for the island of Gotland. However, some limitations should be noted. Firstly, experts were used to estimate the uncertain quantities of input variables. While expert elicitation can be performed in a formal setting, e.g. using the Sheffield Elicitation Framework (Oakley and O'Hagan 2016), the elicitation performed in this study was more informal and was based on group and individual discussions. By using an informal elicitation setting, the risk of biased assessments increases as e.g. more outspoken experts may be given more room in the discussions or experts speaking outside their area of expertise may remain unchallenged. Secondly, local expertise was prioritized as both costs and potentials depend on site-specific conditions. However, by using local expertise the number of previously implemented measures on which estimates can be based becomes limited. This may further impact on the estimated quantities. Thirdly, the scope of this paper was limited to estimations of financial costs and did not allow for inclusion of any ancillary effects, such as environmental improvements or other externalities. Some of these additional effects may be substantial and could change the marginal costs and ranking order if included. It is important to bear these limitations in mind when interpreting the results provided.

As previously mentioned, uncertainties are commonly not considered in MACCs and there is no commonly applied approach for uncertainty and sensitivity analysis. The probabilistic approach proposed here enables a thorough uncertainty analysis where the variation in estimated water availability and cost can be assessed and thus the robustness of the measures evaluated. Furthermore, a comparison of the relative uncertainty of the measures is made possible, and detailed sensitivity analyses could highlight the input variables that contribute 
most to outcome uncertainties. Such information provides a more informed picture of the financial risks and water potentials associated with each measure and could thus affect the perception of which measure is most beneficial. It also facilitates decisions regarding which variables ought to be investigated further in order to reduce uncertainties.

The results show that the agricultural measure of increased irrigation dams may be a costeffective path to improved water availability through overall enhanced storage capacity. The use of on-farm water storage enables farmers to extract water from watercourses at times when the flow is high and store it for use when the flow is low. The large potential of the agricultural sector to contribute to increased water availability through water savings is well known (Dworak et al. 2007; EC 2018). On-farm storage, however, does not typically save water but instead reduces the pressure on water bodies at critical times while securing an irrigation supply and creating recreational and aesthetic benefits (Berman et al. 2012). On an island such as Gotland, with high precipitation runoff, the measure will, in addition to the abovementioned benefits, also help keep the water on the island, improving overall water availability and the potential for multipurpose water use.

The most cost-effective measure analyzed for Gotland was retrofitting showerheads and faucets in the hotel industry. While the theoretical annual volume conserved was rather low due to the limited number of hotels on the island, the MACC confirmed that there may be significant cost savings to be made when focusing on measures designed to save hot water. This is in line with previous findings, as reduced hot water usage leads to reduced energy consumption (Fidar et al. 2016). In general, many water-saving measures and technical devices available to the tourism sector, such as efficient faucets and dishwashers, are similar to those available to households. The measures are often easy to implement and have short payback periods (Dworak et al. 2007). The household measures analyzed in this study were, however, the least cost-effective measures. The high unit costs were due in part to treatment technologies needed to meet the quality requirements. While other studies have found rainwater harvesting economically beneficial for non-potable outdoor use, e.g. Dallman et al. (2016), the potable use requirement in this study made it uneconomical. In addition, it was assumed that all household measures were implemented in each household even though for some of the measures costs could be lowered by households sharing the systems.

Of the municipal supply measures, conventional groundwater and surface water extraction were shown to be more cost-effective than non-conventional desalination. The high energy requirement of desalination is highlighted in the literature as a major limitation of this measure and a reason behind the often high unit costs (Pinto and Marques 2017). On Gotland, the unit cost of desalination was further affected by the long pipelines needed to reach demand centers. The high cost associated with long-distance piping has previously been shown to alter the order of cost-effectiveness of alternative water supply measures (Lamei et al. 2008). The unit cost of desalination on Gotland was about 25 times higher than that of increased groundwater extraction.

The second most cost-effective municipal measure was improved wastewater treatment for irrigation. As agricultural irrigation has been estimated to have high potential to increase uptake of water reuse, encouragement of this measure was one of the main objectives in the recent European Commission proposal on minimum requirements for water reuse (EC 2018). In addition to the low unit costs on Gotland, this measure may also provide several co-benefits that are not considered in this study, such as improved water quality in nearby watercourses, increased groundwater recharge, and reduced eutrophication of the Baltic Sea. 
Even though some measures are highly cost-effective, existing barriers could hinder implementation and hence the possibility of improving the situation. These barriers may be financial, e.g. high initial capital costs, legal, e.g. environmental permits, or social, e.g. lack of awareness of measure efficiency (Addams et al. 2009). To overcome these barriers, some form of policy intervention is usually needed. The MACC provided does not include information on policy instruments to enhance measure implementation. MACCs can, however, be used to guide policy development by helping policymakers identify which measures need an extra push (Vogt-Schilb et al. 2014). To further facilitate fact-based guidance in policy design, more detailed information on drivers and barriers will be gathered and included in future research.

When comparing investments of unequal useful lives, either the equivalent annual cost approach or the replacement chain method is normally used (Brigham and Ehrhardt 2008). The equivalent annual cost approach involves estimating the (net) present value for each measure over its lifetime and dividing it by the lifetime annuity discount factor. The replacement chain method involves repeating the measure investment over the least common useful lifetime. Most MACC studies use the former approach, i.e. life-cycle based costs, to compare individual measures, see Ibrahim and Kennedy (2016). In this paper, the replacement chain method is applied to calculate present values for each measure over a common time horizon. The present values are then calculated as equivalent annual costs distributed evenly over the time horizon. Although this arrangement is not the typical MACC approach, it is used here as it allows fair comparisons to be made between measures over long time horizons (IMWG 2013).

Traditional MACC studies normally assume that analyzed measures will be implemented in sequence, from the least to the highest cost per unit (Dunant et al. 2019). Furthermore, the individual measures are normally totaled to reveal the overall potential of all the measures. This means that account must be taken of possible interactions between measures, e.g. when the implementation of one measure changes the water availability potential of another measure. Such interactions can and should be considered when calculating a cumulative potential, by e.g. adjusting the potential of the interacting measures (Addams et al. 2009). However, as actual implementation does not necessarily follow the order of cost-effectiveness, and as the aim in this paper was to visualize the water availability potential of each measure and not the cumulative potential, the MACC was constructed without taking possible interactions into account.

Finally, it should be mentioned that the process of deriving a MACC is as valuable as the final result (Eory et al. 2018a). The process necessitates the involvement of many stakeholders and encourages communication between water providers, farmers, industry and public authorities. It thus improves overall awareness of inter-sectorial challenges and possible ways to address and overcome them. The presented approach provides a quantitative visualization of the range of possible measures and a common framework for the discussions surrounding water scarcity mitigation. The MACC approach presented here will be further developed to include externalities, seasonal and spatial variability, interactions between measures, barriers to implementation, and feasible policy instruments.

\section{Conclusions}

The main conclusions of this paper are:

- This study presents the procedure behind using a MACC approach to assess water scarcity mitigation measures. It provides an informative tool that can guide businesses, households, 
farmers and municipalities. It sets the scene for targeted measures and strategic investments, along with a better decision-making basis on the societal level for determining which measures and sectors to prioritize from a cost-effectiveness perspective.

- The process of constructing MACCs requires the involvement of many stakeholders, greatly improving the awareness and understanding of sectorial challenges and possibilities. The easily understandable format further facilitates stakeholder dialogue on how to improve societal preparedness and resilience to the challenges posed by water scarcity.

- Improving previous MACC formats by incorporating systematic handling of uncertainties, offers public and private managers an opportunity to attain a higher level of water security and to do so in a well-informed manner. Furthermore, it enhances the transparency of the uncertainties and assumptions involved in a way that they can be addressed and considered.

- The utilization of the MACC approach has provided valuable information regarding the future direction of water scarcity mitigation on the island of Gotland. In addition to guidance on measures, the results may also enable identification of areas in which policy instruments are needed to facilitate implementation.

Acknowledgements Open access funding provided by RISE Research Institutes of Sweden. This research was performed at the DRICKS center for drinking water research at Chalmers University of Technology. The work was funded by the European Union Horizon 2020 research and innovation program under Marie SkłodowskaCurie Grant Agreement No. 754412; Region Västra Götaland; Region Gotland; Swedish Agency for Economic and Regional Growth; and Swedish Research Council Formas Contract No. 942-2015-130. Many thanks to Mikael Tiouls and Lars Westerlund at Region Gotland, Andreas Nypelius at the Federation of Swedish Farmers (LRF), Christina Huhtsaari formerly at the Swedish Board of Agriculture, and Frida Eklund at the County Administrative Board of Gotland, as well as all other experts and stakeholders who have contributed with discussions on mitigation measures.

\section{Compliance with Ethical Standards}

Conflict of Interest The authors declare that they have no conflict of interest.

Open Access This article is distributed under the terms of the Creative Commons Attribution 4.0 International License (http://creativecommons.org/licenses/by/4.0/), which permits unrestricted use, distribution, and reproduction in any medium, provided you give appropriate credit to the original author(s) and the source, provide a link to the Creative Commons license, and indicate if changes were made.

\section{References}

Addams L, Boccaletti G, Kerlin M, Stuchtey M (2009) Charting our water future - economic frameworks to inform decision-making. 2030 Water Resources Group

Berman S, Jana U, Hoa E, Lavelle P, Geoffroy C, Hess T, Knox J, Postle M, Fenn T, Upson S, Sonigo P (2012) A water availability MACC is Water saving potential in agriculture in Europe: findings from the existing studies and application to case studies. European Comission DG ENV

Black J, Hashimzade N, Myles G (2017) A dictionary of economics (5 ed.). Oxford University Press, Oxford Brealey RA, Myers SC, Allen F (2010) Principles of corporate finance, 10th edn. McGraw-Hill/Irwin, New York Brigham E, Ehrhardt M (2008) Financial management: Theory \& Practice, 12th edn. Thomson South-Western, Mason

Chukalla AD, Krol MS, Hoekstra AY (2017) Marginal cost curves for water footprint reduction in irrigated agriculture: guiding a cost-effective reduction of crop water consumption to a permit or benchmark level. Hydrol Earth Syst Sci 21(7):3507-3524

County Administrative Board of Gotland (2018) Regional Water Supply Plan of Gotland. Visby, Sweden: County Administrative Board of Gotland 
Dallman S, Chaudhry AM, Muleta MK, Lee J (2016) The value of rain: benefit-cost analysis of rainwater harvesting systems. Water Resour Manag 30(12):4415-4428

Dukhovny VA, Sokolov VI, Ziganshina DR (2013) Integrated Water Resources Management in Central Asia, as a way of survival in conditions of water scarcity. Quat Int 311:181-188

Dunant CF, Skelton ACH, Drewniok MP, Cullen JM, Allwood JM (2019) A marginal abatement cost curve for material efficiency accounting for uncertainty. Resour Conserv Recycl 144:39-47

Dworak T, Berglund M, Laaser C, Strosser P, Roussard J, Grandmougin B, Kossida M, Kyriazopoulou I, Berbel J, Kolberg S, Rodríguez-Díaz JA, Montesinos P (2007) EU water saving potential. Ecologic Institute for International and European Environmental Policy, Berlin

EC (2007) Addressing the challenge of water scarcity and droughts in the European Union. COM/2007/0414 final. Brussels, Belgium: European Commission.

EC (2018) Proposal for a REGULATION OF THE EUROPEAN PARLIAMENT AND OF THE COUNCIL on minimum requirements for water reuse. COM/2018/337 final - 2018/0169 (COD). Brussels, Belgium: European Commission

Eory V, Pellerin S, Carmona Garcia G, Lehtonen H, Licite I, Mattila H, Lund-Sørensen T, Muldowney J, Popluga D, Strandmark L, Schulte R (2018a) Marginal abatement cost curves for agricultural climate policy: state-ofthe art, lessons learnt and future potential. J Clean Prod 182:705-716

Eory V, Topp CFE, Butler A, Moran D (2018b) Addressing uncertainty in efficient mitigation of agricultural greenhouse gas emissions. J Agric Econ 69(3):627-645

Eurostat (2017) Water statistics. Retrieved July 5, 2019, from https://ec.europa.eu/eurostat/statisticsexplained/index.php/Water_statistics:Eurostat

Fidar AM, Memon FA, Butler D (2016) Performance evaluation of conventional and water saving taps. Sci Total Environ 541:815-824. https://doi.org/10.1016/j.scitotenv.2015.08.024

Garvey PR, Book SA, Covert RP (2016) Probability methods for cost uncertainty analysis: a systems engineering, Second edn. CRC Press, New York

Hastings NAJ (2015) Physical asset Managment: with an introduction to ISO55000. Springer International Publishing, Cham

Ibrahim N, Kennedy C (2016) A methodology for constructing marginal abatement cost curves for climate action in cities. Energies 9(4):227

IMWG (2013) Beregningsmetode til samfundsøkonomiske omkostninger ved virkemidler i klimaplan. Catalogue of Danish Climate Change Mitigation Measures - Reduction potentials and costs of climate change mitigation measures. Inter-ministerial working group. The Danish Ministry of Climate, Energy and Building

Kesicki F (2010) Marginal abatement cost curves for policy making - expert-based vs. model-derived curves. Paper presented at the the 33rd IAEE International Conference, Rio de Janeiro, Brazil

Kesicki F (2012) Decomposing long-run carbon abatement cost curves - robustness and uncertainty. (Doctor of Philosophy), UCL University College London

Lamei A, van der Zaag P, von Münch E (2008) Basic cost equations to estimate unit production costs for RO desalination and long-distance piping to supply water to tourism-dominated arid coastal regions of Egypt. Desalination 225(1-3):1-12. https://doi.org/10.1016/j.desal.2007.08.003

Moran D, Macleod M, Wall E, Eory V, McVittie A, Barnes A, Rees B, Pajot G, Matthews R, Smith P, Moxey A (2009) Marginal abatement cost curves for UK agriculture, forestry, land-use and land-use change sector out to 2022. IOP Conf Ser: Earth Environ Sci 6(24):242002. https://doi.org/10.1088/1755-1307 $/ 6 / 24 / 242002$

Oakley JE, O'Hagan A (2016) SHELF: the Sheffield Elicitation Framework (version 3.0): School of Mathematics and Statistics, University of Sheffield, UK. http:/tonyohagan.co.uk/shelf Accessed 11 Apr 2019

Peng B-B, Xu J-H, Fan Y (2018) Modeling uncertainty in estimation of carbon dioxide abatement costs of energy-saving technologies for passenger cars in China. Energy Policy 113:306-319. https://doi.org/10.1016 /j.enpol.2017.11.010

Pinto FS, Marques RC (2017) Desalination projects economic feasibility: a standardization of cost determinants. Renew Sust Energ Rev 78:904-915. https://doi.org/10.1016/j.rser.2017.05.024

Region Gotland (2017) Gotland in numbers (Gotland i siffror). https://www.gotland.se/64224. Accessed 12 Sept 2018

Rosenberg DE (2007) Probabilistic estimation of water conservation effectiveness. J Water Resour Plann Manage 133(1):39-49

Sjökvist E, Abdoush D, Axén J (2019) The summer 2018 - a glimpse of the future? (Vol. KLIMATOLOGI 52). Norrköping, Sweden: Swedish Meteorological and Hydrological Institute

Statistics Sweden (2017) Water Use in Sweden 2015. Stockholm, Sweden: Statistics Sweden, Unit of Environmental Accounts

Stern N (2006) Stern Review: The Economics of Climate Change. Government of the United Kingdom: Grantham Research Institute on Climate Change and the Environment 
Swedish Transport Administration (2018) Analysis method and socio-economic cost and benefit values for the transport sector: ASEK 6.1.: Swedish Transportation Administration

Vogt-Schilb A, Hallegatte S, de Gouvello C (2014) Marginal abatement cost curves and the quality of emission reductions: a case study on Brazil. Clim Pol 15(6):703-723. https://doi.org/10.1080/14693062.2014.953908

WEF (2019) The Global Risk Report 2019, 14th Edition. World Economic Forum

Westling K, Kärrman E, Norström A (2019) A vision for water - Research and innovation agenda for the Swedish water sector. Retrieved August 19, 2019 from https://www.svensktvatten.se/forskning/vattenplattformen/vattenvisionen/

Worrell E, Martin N, Price L (2000) Potentials for energy efficiency improvement in the US cement industry. Energy 25(12):1189-1214

Publisher's Note Springer Nature remains neutral with regard to jurisdictional claims in published maps and institutional affiliations.

\section{Affiliations}

\section{Karin Sjöstrand ${ }^{1,2} \cdot$ Andreas Lindhe $^{2} \cdot$ Tore Söderqvist $^{3} \cdot$ Peter Dahlqvist $^{4} \cdot$ Lars Rosén $^{2}$}

Karin Sjöstrand

karin.sjostrand@ri.se

1 RISE Research Institutes of Sweden, Scheelevägen 27, SE-223 70 Lund, Sweden

2 Department of Architecture and Civil Engineering, Chalmers University of Technology, SE-412 96 Göteborg, Sweden

3 Anthesis Enveco, Barnhusgatan 4, SE-111 23 Stockholm, Sweden

4 Geological Survey of Sweden, Kiliansgatan 10, SE-223 50 Lund, Sweden 